\title{
Microcolumn development on titanium by multipulse laser irradiation in nitrogen
}

\author{
E. György, ${ }^{\text {a) }}$ A. Pérez del Pino, P. Serra, and J.L. Morenza ${ }^{\text {b) }}$ \\ Universitat de Barcelona, Departament de Física Aplicada i Òptica, Avda. Diagonal 647, \\ E-08028 Barcelona, Spain
}

(Received 7 April 2003; accepted 25 June 2003)

\begin{abstract}
We report the growth of titanium nitride microcolumns under multipulse Nd:yttrium aluminum garnet $(\lambda=1.064 \mu \mathrm{m}, \tau \sim 300 \mathrm{~ns}, \nu=30 \mathrm{kHz})$ laser irradiation of titanium targets in nitrogen atmosphere. The laser intensity value was chosen below the single-pulse melting threshold of titanium. The evolution with the number of laser pulses of the target morphology, crystalline state, and chemical composition at the surface as well as in depth were investigated by scanning electron microscopy, $x$-ray diffractometry, Raman spectroscopy, and wavelength dispersive x-ray spectroscopy. Under the action of the laser pulses, during progressive surface nitridation, an initial rippled morphology developed, which evolved with further irradiation to TiN microcolumns. In-depth investigations showed a granular zone beneath the surface consisting of rutile and anatase phase $\mathrm{TiO}_{2}$, followed by a compact needlelike layer of titanium until the interface with the unaffected target material.
\end{abstract}

\section{INTRODUCTION}

Titanium has interesting properties such as lightness, thermal stability, and biocompatibility, which make it suitable for industrial and medical applications. ${ }^{1}$ However, drawbacks such as poor wear resistance and low hardness limit the number of potential applications. To overcome these inconveniences, different surface techniques have been used, such as conventional furnace heating, plasma processing, or ion implantation. The change of the surface structure and/or chemical composition improves these properties over those of the bulk, corresponding to the requirements of the specific applications.

As an alternative technique, processing of the titanium surface with laser radiation has attracted considerable interest during the last decade. ${ }^{2,3}$ Its main advantages over the conventional techniques are the accurate spatial control of the process and the short processing time. Among its possible applications stand surface compound layers formation, as nitridation or oxidation in controlled reactive atmosphere, surface structuring, smoothing, and hardening.

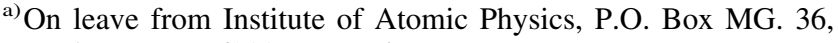
Bucharest V, 76900, Romania. e-mail: eniko@ifin.nipne.ro

b) Address all correspondence to this author. e-mail: jmorenza@fao.ub.es
}

Laser scanning treatment of titanium surface in high-pressure nitrogen allowed us to grow high-quality titanium nitride thin layers with a smooth surface morphology. ${ }^{4,5}$ Moreover, laser multipulse irradiation of titanium at low laser intensities, below or in some cases just above the single-pulse melting threshold of $\mathrm{Ti}^{6}$ in air or vacuum, led to the development of a large variety of surface morphologies: crown ${ }^{7}$ or dome-shaped ${ }^{8}$ microstructures or dendritic-shaped microrelief. ${ }^{9}$

On the other hand, columnar microstructures were recently reported to grow on titanium surface during multipulse laser irradiation in low $(1 \mathrm{~Pa})$ vacuum. ${ }^{10}$ Similar columnar structures were also reported to grow on silicon, ${ }^{11,12}$ or ceramic composites ${ }^{13}$ in oxygen-containing atmospheres. However, we could not find in the literature columnar titanium nitride microstructures, neither on the surface of irradiated $\mathrm{TiN}$ nor $\mathrm{Ti}$ in reactive nitrogen atmosphere. Nevertheless, TiN surface microcolumns could be interesting for field electron-emission devices ${ }^{14}$ and medical applications. ${ }^{1}$ Our purpose was to investigate the effects of low intensity multipulse laser irradiation on Ti surfaces in nitrogen, as well as the possibility of columnar microstructure creation, and in this work we present the obtained results.

\section{EXPERIMENTAL}

The targets submitted to multipulse laser irradiation consisted of $10 \times 10 \times 1 \mathrm{~mm}^{3}$, polished, high purity (99.6\%), hexagonal phase $\alpha-\mathrm{Ti}$ foils. The experiments were conducted with a Baasel LBI $6000 \mathrm{Nd}$ :yttrium 
aluminum garnet (YAG) $(\lambda=1.064 \mu \mathrm{m})$ laser system (Baasel Lasertech, Germany) generating pulses of $300 \mathrm{~ns}$ with nearly Gaussian temporal shape. The spatial intensity distribution was characterized by a nearly Gaussian circular intense central zone with a diameter of $120 \mu \mathrm{m}$ on the target surface. The total beam diameter on the target was $500 \mu \mathrm{m}$. The total laser pulse energy was fixed at $2 \mathrm{~mJ}$, corresponding to about $1 \mathrm{~mJ}$ in the central zone of the beam. Thus, the laser intensity in the central zone was about $30 \mathrm{MW} / \mathrm{cm}^{2}$, and in the surrounding more than one order of magnitude lower. These intensity values are below the single-pulse melting threshold of Ti. ${ }^{6}$ The laser beam was incident normally to the $\mathrm{Ti}$ target surface. Up to 30,000 laser pulses at a repetition rate of $30 \mathrm{kHz}$ were directed onto the same target location through a $100 \mathrm{~mm}$ focal lens. The irradiations were performed in a stainless steel vacuum chamber preliminary pumped down to a residual pressure of $2 \times 10^{-4} \mathrm{~Pa}$, and then filled with pure (less than $3 \mathrm{ppm}$ oxygen contamination) nitrogen at a pressure of $3 \times 10^{4} \mathrm{~Pa}$. The Ti sample surfaces further submitted to the different diagnostic techniques were covered by many identical imprints to increase the analysis area.

The surface morphology evolution was investigated by scanning electron microscopy (SEM) with a Jeol JSM 840 (Japan) and a Cambridge S120 microscope (Cambridge Instruments, United Kingdom). To investigate the crystalline structure, the samples were subjected to $\mathrm{X}$-ray diffractometry (XRD) analyses using a Bragg-Brentano diffractometer (Siemens D500, Germany) in $\theta-2 \theta$ configuration. The $\mathrm{Cu} \mathrm{K}$ radiation $(\lambda=0.154 \mathrm{~nm})$ was chosen for excitation. The chemical composition was analyzed by Raman spectroscopy and wavelength dispersive $\mathrm{x}$-ray spectroscopy (WDX). The Raman spectra were recorded in backscattering configuration, with a Jobin-Yvon T64000 spectrometer (Jobin-Yvon Ltd., United Kingdom) equipped with an optical microscope. For excitation, the $514.5 \mathrm{~nm}$ line of the $\mathrm{Ar}^{+}$ion laser was focused with a 50x objective over a $2-\mu \mathrm{m}$-diameter spot area on the sample surface, with $120 \mathrm{~s}$ integrating time per scan. The laser power on the sample was $9 \mathrm{~mW}$. The WDX studies were performed with a Cameca Camebax SX-50 (Cameca, France) equipment $(15 \mathrm{kV}, 100 \mathrm{nA}, 2 \mathrm{~s}$ integrating time per point).

\section{RESULTS}

The evolution of the surface morphology as a function of the number of applied laser pulses is presented in Fig. 1. An initial microrelief with a molten aspect is observed after 390 laser pulses [Fig. 1(a)] characterized by an irregular surface modulation with a height of about $1 \mu \mathrm{m}$. With the increase of the number of pulses to 810 [Fig. 1(b)] a rippled structure develops constituted by small, submicrometer-sized hills, still connected to each other. Further increasing the laser pulse number to 1200 [Fig. 1(c)], the morphology changes to a dense and uniform structure, with the hills protruding 2-3 $\mu \mathrm{m}$ above the nonirradiated surface level. The hill diameters as well as the space between them reach about $1-1.5 \mu \mathrm{m}$. The structure further develops under the action of the next laser pulses [Fig. 1(d)], and irradiation with 2400 pulses leads to about $10 \mu \mathrm{m}$ tall columns [Fig. 1(e)]. However, a saturation effect is observed in the structure development with a maximum column height of about $10-15 \mu \mathrm{m}$. The further irradiation leads to a gradual decrease of the structures aspect ratio by the decrease of
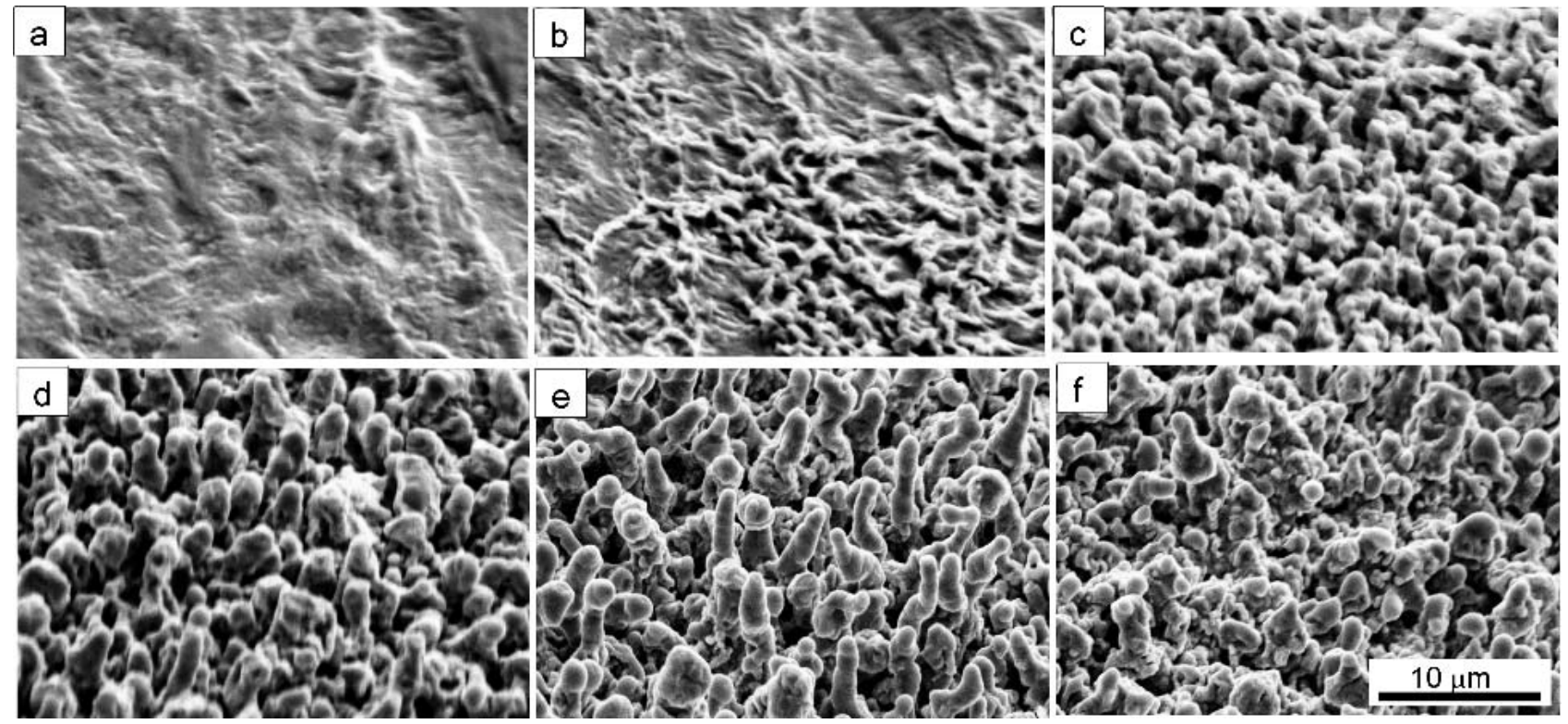

FIG. 1. SEM micrographs of the central area of the imprints obtained with (a) 390, (b) 810, (c) 1200, (d) 1500, (e) 2400, and (f) 3900 laser pulses (magnification is the same for all images). The samples were tilted $50^{\circ}$. 
the columns heights and the increase of their diameters [Fig. 1(f)]. It is to be noted that when the number of subsequent laser pulses exceeds 1500 , weak plasma is ignited in front of the irradiated target area.

Similar morphology evolution takes place also at the border of the imprints, where the laser intensity is lower as compared to the central part. However, a higher number of pulses is necessary for the columns formation, and their heights remain below the level characteristic for the columns of the central zone.

In the cross-section SEM micrographs of the imprints obtained with 2400 and 30,000 laser pulses (Fig. 2) it can be observed that below the columnar morphology the depth of the heat-affected zone reaches $60 \mu \mathrm{m}$ [Fig. 2(a)] and $130 \mu \mathrm{m}$ [Fig. 2(b)], respectively. The surface of the imprint obtained with 2400 laser pulses is covered by microcolumns growing perpendicularly to the irradiated surface [Fig. 2(c)]. The zone beneath the columns is composed by micrometer-sized grains, until a depth of about $15 \mu \mathrm{m}$, followed by a compact structure consisting of randomly distributed lamellae [Fig. 2(d)]. On the surface of the imprint obtained with 30,000 laser pulses [Fig. 2(e)] the columns are shorter and thicker than those shown in Fig. 2(c). Furthermore, beneath the microcolumns the granular layer visible in Fig. 2(f) is followed in depth by a more compact zone [Fig. $2(\mathrm{~g})]$, and then by a needlelike structure perpendicular to the surface [Fig. 2(h)]. The transition zone to reach the unaffected Ti [Fig. 2(b)] has a less ordered morphology.

The x-ray diffractograms corresponding to the surface of the multi-imprints samples are shown in Fig. 3. The diffractogram of the imprints obtained with 2100 laser pulses [Fig. 3(a)] contains the characteristic pattern of the cubic $\delta$-TiN phase. With the increase of the laser pulse number to 30,000 the intensities of all peaks assigned to the cubic $\delta$-TiN phase rise [Fig. 3(b)]. The presence of
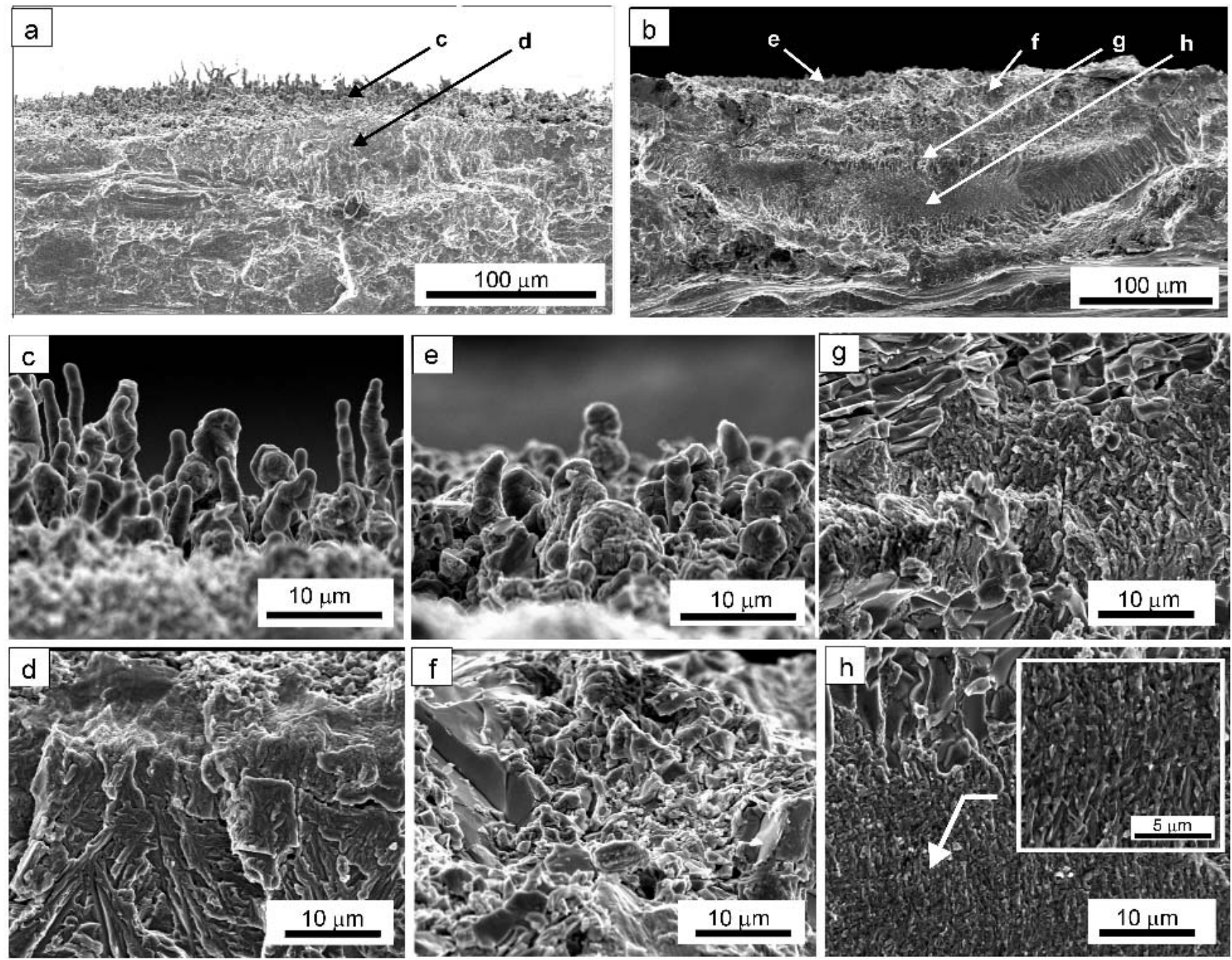

FIG. 2. Cross-section SEM micrographs of the imprints obtained with (a) 2400 and (b) 30,000 laser pulses. Details of (a) show (c) the surface microcolumns and the granular morphology beneath, and (d) the compact structure in the depth: details of (b) from the surface toward the depth showing successively (e) the microcolumns, (f) the granular morphology, (g) the compact zone, and (h) the needlelike structure. 
the hexagonal $\alpha-$ Ti peaks and their satellites corresponding to the hexagonal $\alpha-\operatorname{Ti}(\mathrm{N})$ phase can be attributed to the interimprints nonirradiated zones. No peaks corresponding unambiguously to tetragonal $\mathrm{Ti}_{2} \mathrm{~N}$ or titanium oxide phases can be identified.

The Raman spectra taken on the surface of the imprints obtained with 990, 1500, 2400, and 30,000 laser pulses are presented in Fig. 4. We recall that the first-order Raman spectrum is forbidden for 1:1 stoichiometry, perfect TiN crystal. ${ }^{16}$ However, for almost stoichiometric $\operatorname{TiN}_{x}$, with $x=0.995$ the first order scatterings were reported at 200,285 , and $520 \mathrm{~cm}^{-1} \cdot{ }^{17}$ As compared to these values, in our spectra, the Raman bands are shifted toward higher wave numbers, and this shift decreases when the number of laser pulses increases. In Refs. 16 and 17, the continuous shift toward higher wave numbers was associated with the decreasing nitrogen concentration of the $\operatorname{TiN}_{x}$ samples. Thus, the band positions in the spectrum of the imprint obtained with 30,000 laser pulses indicate the closest N/Ti atomic ratio to the 1:1 stoichiometry. Moreover, the intensity of all bands increases with the increase of the number of laser pulses. In

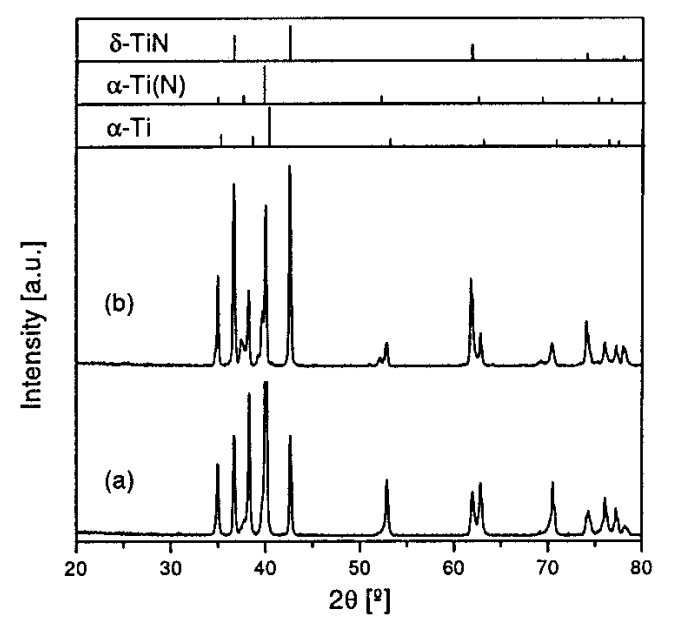

FIG. 3. X-ray diffractograms of the imprints obtained with (a) 2400 and (b) 30,000 laser pulses. The phase identification patterns correspond to Ref. 15.

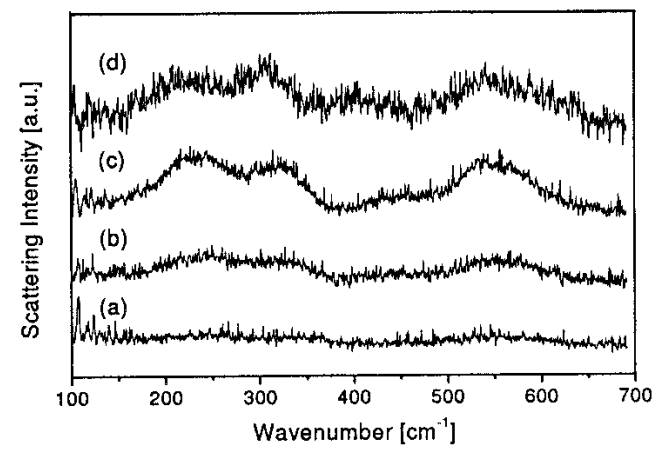

FIG. 4. Raman spectra taken on the surface of the imprints obtained with (a) 990, (b) 1500, (c) 2400, and (d) 30,000 laser pulses.
Ref. 17, the increase of the bands intensity was attributed to the increase of the N/Ti atomic ratio. According to these results the $\mathrm{TiN}_{x}$ surface stoichiometry evolves progressively, $x$ increasing with the increase of the number of laser pulses. On the other hand, new bands at about $440 \mathrm{~cm}^{-1}$ can be identified in the spectrum of the imprint obtained with 2400 pulses, and at about 440 and $610 \mathrm{~cm}^{-1}$ for that obtained with 30,000 pulses. However, their intensity is reduced as compared to the Ti-N bands, and can be assigned to the $\mathrm{TiO}_{2}$ rutile phase. ${ }^{18,19}$ Moreover, the weak band at $140 \mathrm{~cm}^{-1}$ in the spectrum of the imprint obtained with 30,000 laser pulses could correspond to the $\mathrm{TiO}_{2}$ anatase phase. The broad band at about $440 \mathrm{~cm}^{-1}$ could include the $\mathrm{TiO}_{2}$ anatase band at $400 \mathrm{~cm}^{-1}$. However, as reported, the intensity of this $\mathrm{TiO}_{2}$ anatase band should be very low as compared to that at $140 \mathrm{~cm}^{-1} \cdot{ }^{18,20}$ No bands corresponding to $\mathrm{Ti}_{2} \mathrm{O}_{3}$ are present in the spectra, and as regards the lower oxidized phases $\mathrm{Ti}_{2} \mathrm{O}$ and $\mathrm{TiO}$, it must be noted that they are not Raman active.

The Raman spectra [Figs. 5(A.a) and 5(B.a)] recorded on the cross section of the imprints presented in Fig. 2 at a depth of a few micrometers from the surface consist of the characteristic Ti-N bands, similar to those recorded on the surface [Figs. 4(c) and 4(d)]. Conversely, the spectra taken below the nitrided surface, from the surface toward the depth [Figs. 5(A.b-e) and 5(B.b-g)] and from the center toward the periphery [Figs. 5(C) and 5(D)], are completely different to those taken on the surface. All these spectra show the characteristic bands of the $\mathrm{TiO}_{2}$ rutile and anatase phases, with the relative increase of the anatase band from the surface toward the depth. We notice that the bands are shifted from the reported values 240, 447, and $612 \mathrm{~cm}^{-1}$ for the $\mathrm{TiO}_{2}$ rutile phase, ${ }^{18-20}$ and $143 \mathrm{~cm}^{-1}$ for the $\mathrm{TiO}_{2}$ anatase phase. ${ }^{18}$ The shift of the $447 \mathrm{~cm}^{-1}$ rutile $\mathrm{TiO}_{2}$ band toward lower values, and the $143 \mathrm{~cm}^{-1}$ anatase $\mathrm{TiO}_{2}$ band toward higher values were associated with the decrease of the $\mathrm{O} / \mathrm{Ti}$ atomic ratio. ${ }^{18}$ Thus, the peak positions of the bands in the spectra recorded close to the surface of the imprints indicate the highest $\mathrm{O} / \mathrm{Ti}$ ratio, decreasing toward both the depth [Figs. 5(A) and 5(B)] and the periphery [Figs. 5(C) and 5(D)]. As can be observed in Fig. 5(B), the $\mathrm{O} / \mathrm{Ti}$ ratio reaches a minimum value for depths larger than about $9 \mu \mathrm{m}$.

The WDX depth profile taken on the cross section [Fig. 6(a)] shows a high oxygen content until a depth of about $10 \mu \mathrm{m}$, followed by a fast decrease, reaching the level characteristic for the nonirradiated material for depths larger than about $14 \mu \mathrm{m}$. In the evaluation of these values we considered that the signals until a depth of about $4 \mu \mathrm{m}$ correspond to the less compact columnar zone, which surpasses the nonirradiated surface level. The nitrogen content cannot be accurately determined due to the superposition of its energy peak with that of 

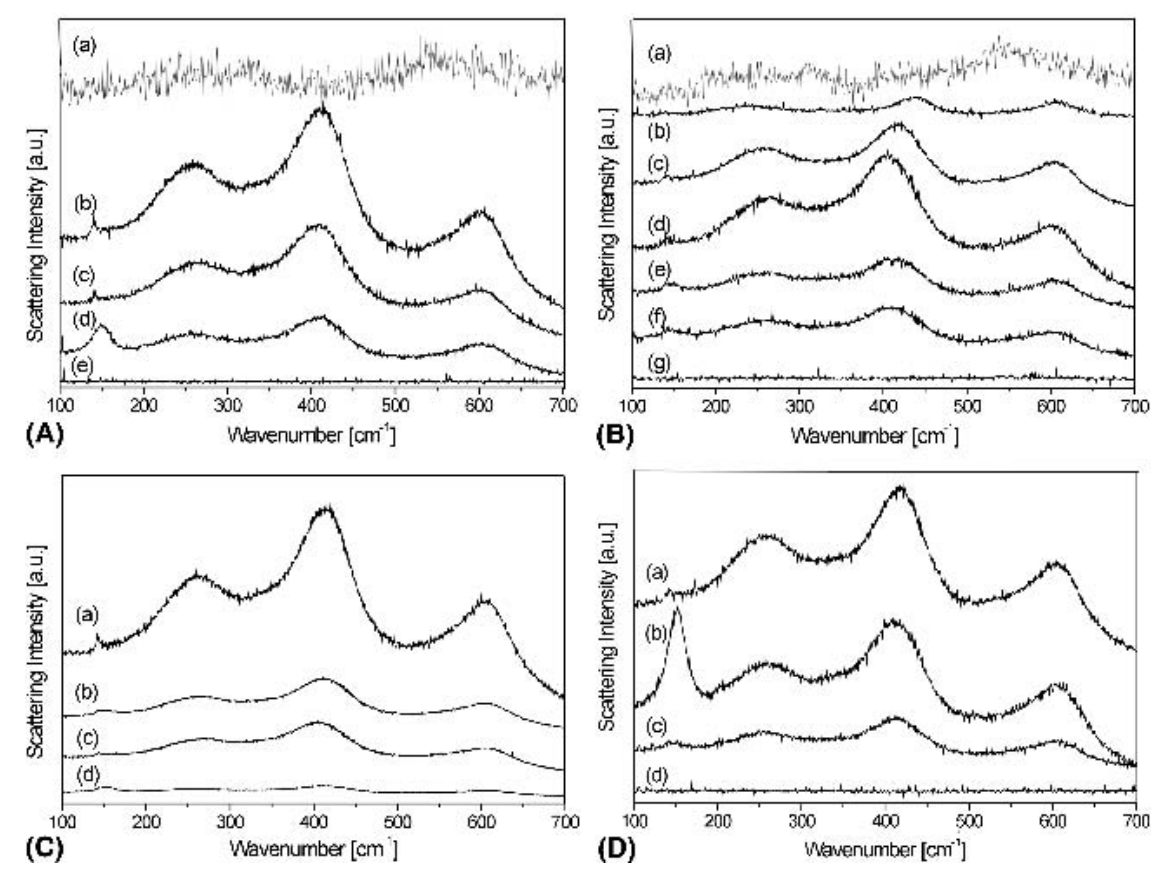

FIG. 5. Raman spectra taken on the cross section of the imprints, along the axis of the imprints obtained with (A) 2400 pulses at depths of (a) $2 \mu \mathrm{m}$, (b) $4 \mu \mathrm{m}$, (c) $6 \mu \mathrm{m}$, (d) $9 \mu \mathrm{m}$, and (e) $12 \mu \mathrm{m}$, and (B) 30,000 pulses at depths of (a) $2 \mu \mathrm{m}$, (b) $4 \mu \mathrm{m}$, (c) $6 \mu \mathrm{m}$, (d) $8 \mu \mathrm{m}$, (e) $10 \mu \mathrm{m}$, (f) $12 \mu \mathrm{m}$, and (g) $15 \mu \mathrm{m}$, measured from the surface; out of the axis of the imprints obtained with (C) 2400 pulses, at a depth of $4 \mu \mathrm{m}$ from the surface and a distance from the axis of (a) $0 \mu \mathrm{m}$, (b) $10 \mu \mathrm{m}$, (c) $20 \mu \mathrm{m}$, and (d) $40 \mu \mathrm{m}$, and (D) 30,000 pulses, at a depth of $6 \mu \mathrm{m}$ from the surface and a distance from the axis of (a) $0 \mu \mathrm{m}$, (b) $40 \mu \mathrm{m}$, (c) $80 \mu \mathrm{m}$, and (d) $120 \mu \mathrm{m}$.

titanium [Fig. 4(b)]. Nevertheless, the first peak corresponding to an approximately $4-\mu \mathrm{m}$-thick surface layer can be attributed to this superposition, suggesting the decrease of the nitrogen concentration when the oxygen content rises. Moreover, below the nitrided surface layer, toward the depth, the signal can be assigned solely to titanium.

\section{DISCUSSION}

High repetition rate laser irradiation induces a progressive rise of the surface temperature ${ }^{21}$ due to the reduced heat diffusion in the short time between two successive pulses. Moreover, the cumulative action of the laser pulses on the target induces the creation of lattice defects, which in turn cause the decrease of the melting threshold. In addition, the increase of the average surface temperature leads to the reduction of the surface reflectivity, ${ }^{2,3}$ and thus, to an enhanced energy absorption. Also, the surface chemical processes, nitridation and oxidation, contribute to the increase of the surface temperature through the release of the reaction energy (due to their intensive exothermal nature). ${ }^{2,3}$ As a consequence, the solid transits to the liquid phase, even below the single pulse melting threshold of the material. Thus, with the further laser pulses the surface follows the successive melting and re-solidification processes. During each melting and resolidification, the volume change and thermal expansion of the liquid ${ }^{22}$ probably produce an initial microrelief characterized by small hills and valleys [Fig. 1(a)]. Moreover, shock waves could contribute to this microrelief when the temperature surpasses the melting point. ${ }^{23}$

Further irradiation leads to the rippled structures and incipient microcolumns growth [Figs. 1(b) and 1(c)] in the absence of the plasma spike. Specific rippled structures were observed also during TiN creation in liquid phase by laser irradiation of titanium alloys in nitrogen atmosphere. ${ }^{24}$ Indeed, we recall that the XRD (Fig. 3) and Raman spectroscopy (Fig. 4) investigations show the progress of the nitridation process with the increase of the laser pulse number. Thermocapillary motion could be responsible for rippled structure formation, since with the increase of the nitrogen content surface tension driven flows become effective, with positive temperature gradient of the surface tension coefficient. ${ }^{24-26}$

At a higher number of laser pulses, surface melting could be followed by significant vaporization. Indeed, the evolution of the initial rippled structure [Fig. 1(b)] to a columnar microrelief [Fig. 1(d)] takes place in the presence of the laser-generated plasma. Once the rippled structure formed, due to geometrical reasons, the incident energy density is higher ${ }^{27}$ in the valleys perpendicular to the laser beam and preferential vaporization becomes possible. The nonuniform surface evaporation in turn could induce local pressure gradients in the plasma developing in front of the irradiated target. ${ }^{26,28}$ This 


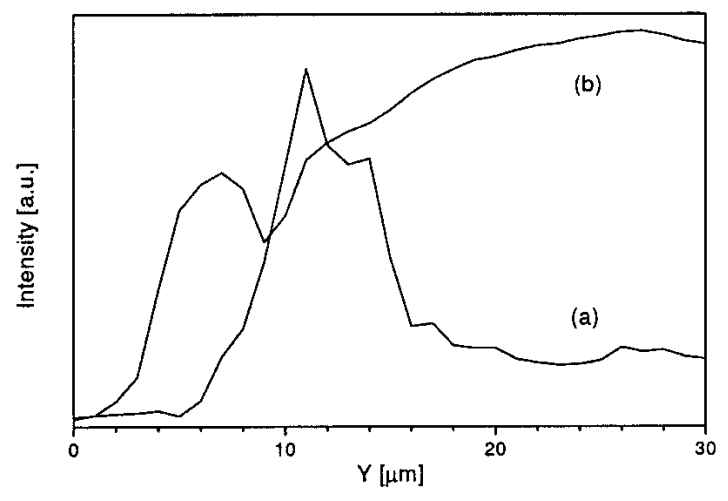

FIG. 6. WDX profiles of (a) oxygen as well as (b) nitrogen and titanium recorded from the surface toward the depth in the central part of the cross section of the imprint obtained with 30,000 laser pulses.

pressure is higher around the columns than on their top, inducing liquid motion upwards and contributing to the initial columns formation.

With further irradiation, the column diameters remain practically unchanged [compare Figs. 1(d) and 1(e)]. On the vertical column walls, the energy density is reduced and probably insufficient for melting. Thus, the columns further growth could be due to vaporization taking place mainly in the zones between the columns and vapor recondensation on their molten top nearly perpendicular to the laser beam. Indeed, the accommodation coefficient of vapor species increases with the increase of the local surface temperature and is close to one on a liquid surface. $^{29,30}$

However, with more laser pulses the meltingvaporization processes become generalized on the whole surface and thus the further development of the columnar structure is no more possible [Figs. 1(f) and 2(e)].

On the other hand, the laser energy absorption remains for the whole irradiation period a surface process, since the optical absorption length does not exceed a few tens of nanometers ${ }^{31}$ due to the metallic character of the forming titanium nitride. Thus, the tens of micrometers large affected zones beneath the surface microcolumns [Figs. 2(a) and 2(b)] could be attributed only to heat diffusion during the high repetition rate multipulse laser irradiation. Nevertheless, according to theoretical considerations for target heating regimes under the action of high repetition rate laser pulses ${ }^{21}$ and our numerical estimations, the temperature of the zones tens of micrometers beneath the surface increases indeed but still remains below the melting threshold of the material.

The results of our Raman spectroscopy and WDX investigations revealed important modifications also in the composition beneath the irradiated surface (Figs. 4-6), besides the different morphologies observed in depth [Figs. 2(c) and 2(h)]. Indeed, beneath the titanium nitride surface microcolumns the granular zone was found to contain rutile and anatase $\mathrm{TiO}_{2}$, while the compact ordered structure was Ti. A recrystallized needlelike structure beneath the nitrided layer in laser irradiated $\mathrm{Ti}$ was reported, ${ }^{32,33}$ and its formation was attributed to the rapid heating and cooling rates during every subsequent laser pulse.

The origin of the subsurface oxide layer could be associated with the oxygen present in the native oxide surface layer. Nevertheless, we did not observe oxides in the x-ray diffractograms or Raman spectra of untreated titanium. Accordingly, this native oxide layer must be very thin and not enough to account for the formation of the thick subsurface oxide layer. Instead, the oxygen traces in the ambient nitrogen could be the cause of the oxide layer. ${ }^{3,4}$ Indeed, oxygen even if present in small quantities in the ambient atmosphere, diffuses much faster into the hot metal getter than nitrogen. ${ }^{34}$ Then, due to the high ambient nitrogen pressure and high surface temperature, with further irradiation a significant enrichment in nitrogen content of the irradiated surface takes place, with the corresponding migration of oxygen atoms from the surface oxide into the bulk metal. ${ }^{34,35}$ On the other hand, the enthalpy of oxides formation is more negative than that of nitrides, ${ }^{36}$ explaining the formation of oxides instead of nitrides at the regions beneath the surface. Furthermore, the heat release during the oxidation processes and trapped gases could contribute to the development of the oxide granular morphology.

Finally, we notice that the evolution of the titanium surface morphology with the increase of the laser pulses to a columnar microstructure is characteristic for the irradiations performed in nitrogen. We did not observe in our previous works the growth of microcolumns either in vacuum or air under similar irradiation conditions. This experimental evidence clearly reveals the importance in the surface morphology evolution of the chemical compound formation, which thermophysical and optical properties will further determine the laser-target energy coupling and absorption process characteristics.

\section{CONCLUSION}

Titanium targets were submitted to multipulse Nd:YAG $(\lambda=1.064 \mu \mathrm{m}, \tau \sim 300 \mathrm{~ns}, \nu=30 \mathrm{kHz})$ laser irradiation in nitrogen, at a laser intensity value below the single-pulse melting threshold of Ti. The rippled structure and microcolumn formation on the surface were associated with laser induced nitridation and hydrodynamic processes driven by capillary waves, as well as pressure gradients in the laser generated plasma developing in the front of the irradiated target. Redeposition of target vapors from the plasma contributes to the columns growth process. The zone beneath the TiN surface microcolumns influenced by the laser treatment extends down to a depth of tens of micrometers. The first granular zone consists of rutile and anatase phase $\mathrm{TiO}_{2}$, while the next 
compact zone is of $\mathrm{Ti}$ showing an ordered needlelike morphology zone probably as a consequence of recrystallization processes.

\section{ACKNOWLEDGMENTS}

This work is a part of a program financed by Ministerio de Ciencia y Tecnología (MCYT) of the Spanish Government (MAT2001-3757) and Department d'Universitats, Recerca i Societat de la Informació (DURSI) of the Catalan Government (2001SGR00080).

\section{REFERENCES}

1. Titanium in Medicine, edited by D.M. Brunette, P. Tengvall, M. Textor, and P. Thomsen (Springer-Verlag, Berlin, Germany, 2001).

2. A.M. Prokhorov, I. Ursu, I.N. Mihailescu, and V.I. Konov, Laser Heating of Metals (Adam Hilger, Bristol, U.K., 1990)

3. D. Bauerle, Laser Processing and Chemistry (Springer-Verlag, Berlin, Germany, 2000)

4. E. Gyorgy, A. Perez del Pino, P. Serra, and J.L. Morenza, Appl. Surf. Sci. 186, 130 (2002)

5. E. Gyorgy, A. Perez del Pino, P. Serra, and J.L. Morenza, Surf. Coat. Technol. 173, 265 (2003).

6. E. Gyorgy, I.N. Mihailescu, P. Serra, A. Perez del Pino, and J.L. Morenza, Surf. Coat. Technol. 154, 63 (2002).

7. E. Gyorgy, I.N. Mihailescu, P. Serra, A. Perez del Pino, and J.L. Morenza, Appl. Phys. A: Mater. Sci. Process. 74, 755 (2002).

8. E. Gyorgy, A. Perez del Pino, P. Serra, and J.L. Morenza, Appl. Phys. A: Mater. Sci. Process. (in press).

9. E. Gyorgy, A. Perez del Pino, P. Serra, and J.L. Morenza, Appl. Surf. Sci. 197-198, 851 (2002).

10. S.I. Dolgaev, S.V. Lavrishev, A.A. Lyalin, A.V. Simakin, V.V. Votonov, and G.A. Shafeev, Appl. Phys. A: Mater. Sci. Process. 73, 177 (2001).

11. F. Sanchez, J.L. Morenza, and V. Trtik, Appl. Phys. Lett. 75, 3303 (1999).

12. A.J. Pedraza, J.D. Fowlkes, and D.H. Lowndes, Appl. Phys. Lett. 74, 2322 (1999).

13. M. Mendes, V. Oliveira, R. Vilar, F. Beinhorn, J. Ihleman, and O. Conde, Appl. Surf. Sci. 154-155, 29 (2000).

14. M. Nakamoto and K. Fukuda, Appl. Surf. Sci. 202, 289 (2002).
15. Powder Diffraction File Nos. 38-1420, 44-1095, 05-0682 (JCPDS International Centre for Diffraction Data, Swarthmore, PA, 1988).

16. W. Spengler, R. Kaiser, A.N. Christensen, and G. Muller-Vogt, Phys. Rev. B 17, 1095 (1978).

17. Y.H. Cheng, B.K. Tay, S.P. Lau, H. Kupfer, and F. Richter, J. Appl. Phys. 92, 1845 (2002).

18. J.C. Parker and R.W. Siegel, Appl. Phys. Lett. 57, 943 (1990).

19. G. Thorwarth, S. Mandl, and B. Rauschenbach, Surf. Coat. Technol. 136, 236 (2001).

20. M.P. Moret, R. Zallen, D.P. Vijay, and S.B. Desu, Thin Solid Films 366, 8 (2000).

21. E.G. Gamaly, A.V. Rode, and B. Luther-Davies, J. Appl. Phys. 85, 4213 (1999).

22. R. Kelly and J. Rothenberg, Nucl. Instrum. Methods B 7/8, 755 (1985).

23. S. Tabuchi, H. Tabata, and T. Kawai, Jpn. J. Appl. Phys. 39, 1268 (2000).

24. A.I. Nwobu, R.D. Rawlings, and D.R.F. West, Acta Mater. 47, 631 (1999)

25. A.B. Kloosterman and J.Th.M. De Hosson, Scripta Metal. Mater. 33, 567 (1995)

26. A.B. Brailovsky, I.A. Dorofeev, A.B. Ezersky, V.A. Ermakov, V.I. Luchin, and V.E. Semenov, Sov. Phys. Tech. Phys. 36, 324 (1991).

27. W.W. Duley, UV Lasers: Effects and Applications in Materials Science (Cambridge University Press, Cambridge, U.K., 1996).

28. A.B. Brailovsky, S.V. Gaponov, and V.I. Luchin, Appl. Phys. A: Mater. Sci. Process. 61, 81 (1995).

29. P.R. Willmott and J.R. Huber, Rev. Mod. Phys. 72, 315 (2000).

30. S. Jesse, A.J. Pedraza, J.D. Fowlkes, and J.D. Budai, J. Mater. Res. 17, 1002 (2002)

31. T.V. Kononenko, S.V. Garnov, S.M. Pimenov, V.I. Konov, V. Romano, B. Borsos, and H.P. Weber, Appl. Phys. A: Mater. Sci. Process. 71, 627 (2000)

32. H. Xin, C. Hu, and T.N. Baker, J. Mater. Sci. 35, 3373 (2000).

33. V.S. Teodorescu, I.N. Mihailescu, E. Gyorgy, A. Luches, M. Martino, L.C. Nistor, J. Van Landuyt, and J. Hermann, J. Mod. Opt. 43, 1773 (1996)

34. I. Ursu, I.N. Mihailescu, I. Gutu, A. Hening, T. Julea, L.C. Nistor, M. Popescu, V.S. Teodorescu, A.M. Prokhorov, V.I. Konov, and V.G. Ralchenko, Appl. Opt. 25, 2720 (1986).

35. G.G. Maksimovich, V.N. Federko, and I.N. Pogrelyuk, in Soviet Materials Science, edited by V.V. Panasyuk (Plenum Press, New York, 1992), p. 135.

36. Handbook of Chemistry and Physics, edited by D.R. Lide (CRC Press, Boca Raton, FL, 2001). 